\title{
The FOMC's Interest Rate Policy: How Long Is the Long Run?
}

\author{
Daniel L. Thornton, Vice President and Economic Adviser
}

$\mathrm{T}$ he Federal Open Market Committee (FOMC) reduced its target for the federal funds rate to effectively zero in December 2008. At its August 2011 meeting, the FOMC announced that it "currently anticipates that economic conditions... are likely to warrant exceptionally low levels for the funds rate at least through mid-2013."1 If this does happen, the funds rate will have been essentially zero for at least four and a half years. This essay points out a potential adverse consequence of this interest rate policy and the simple way that the FOMC could avoid it.

Economists often discuss an interest rate relationship known as the Fisher equation, which says that the nominal interest rate is equal to the real interest rate plus the expected rate of inflation. At the level of an individual economic agent, the Fisher equation is essentially tautological: No one who wants to receive a positive real rate of return would invest in a bond yielding a nominal interest rate of, say, 2 percent if they expected the inflation rate over the holding period of the bond to be 2 percent or higher. In this case, the expected return on such an investment would be zero or negative. The Fisher relationship is thought to hold reasonably well in the aggregate also. Indeed, it is essentially used to extract forward-looking inflation expectations by comparing rates on Treasury coupon bonds with rates on Treasury inflation-protected securities (TIPS) of comparable maturity.

To see how the FOMC's interest rate policy and the Fisher relationship can yield an unfavorable result, it is important to note that most economists believe that economic agents are rational-in the sense that inflation expectations will converge to the actual rate of inflation in the "long run." That is, over a sufficiently long period of time (the long run), the expected rate of inflation should equal the actual rate of inflation. If inflation expectations converge to actual inflation, the FOMC zero interest rate policy implies that (i) both the real rate and the inflation rate will be zero or (ii) one of the two will be positive and the other negative. The problem, of course, is that it's difficult to envision an expanding economy where the real rate is zero or negative.

If the real rate is positive, the inflation rate that is consistent with the FOMC's zero interest rate policy in the long run would need to be negative. Now, there is nothing wrong with a negative equilibrium rate of inflation per se. ${ }^{2}$ However, historically speaking, persistent negative rates of inflation have been often associated with anemic economic growth (e.g., Japan and the Great Depression). Indeed, Jim Bullard, president of the St. Louis Fed, has suggested that the FOMC's "extended period" language "may be increasing the probability of a Japanese-style outcome for the United States"-i.e., with interest rates near zero, deflation, and anemic economic growth.

\section{The only outcome consistent with the Fisher equation holding and the FOMC's zero interest rate policy is that the "long run" is considerably longer than 4.5 years.}

Bullard discusses this issue in the context of a theoretical model that has two equilibriums: a good equilibrium where the policy rate is positive and a bad equilibrium where the policy rate is zero. ${ }^{3}$ In the model the policy rate can get stuck in the bad equilibrium, with nothing in the dynamics of the model that would get out of the bad equilibrium once it got there. This result is undoubtedly determined by the specific characteristics of the model. In the real world of policymaking, however, there is nothing to prevent policymakers from getting out of this situation. And the reason is simple: The policy rate is an administered rate-i.e., one that policymakers choose. The FOMC can raise the rate above zero now or presumably at any time in the future. All it needs to do is to reduce the supply of credit through open market sales of assets. Indeed, two central banks- 
the European Central Bank and the Bank of Canadahave already increased their policy rates from their financial crisis/recession lows. The European Central Bank increased its policy rate 50 basis points and the Bank of Canada increased its policy rate by 75 basis points.

For economists, the long run, medium run, and short run are conceptual periods of time that are linked to the details of economic theory but are difficult to define precisely in terms of calendar time. In some applications, the long run might be a few months; in others, a period of years. By keeping the funds rate at zero for the past 26 months and suggesting that it will maintain the zero rate for another two years, the FOMC is effectively saying that the long run for the convergence of inflation expectations to a rate that is consistent with its zero interest rate policy is longer than 4.5 years. This seems exceptionally long. Alternatively, the FOMC might anticipate that inflation expectations will be stabilized close to their implied inflation objective of about 2 percent. Hence, the only outcome that is consistent with the Fisher equation holding and the FOMC's zero interest rate policy is that the long run is considerably longer than 4.5 years.
${ }^{1}$ FOMC press release, August 9, 2011.

2 Milton Friedman once suggested that the optimal equilibrium rate of inflation was negative-in particular, equal to the negative of the economy's real growth rate.

${ }^{3}$ James Bullard, "Seven Faces of "The Peril," Federal Reserve Bank of St. Louis Review, September/October 2010, 92(5), pp. 339-52. Bullard refers to this paper: Benhabib, Jess; Schmitt-Grohé, Stephanie and Uribe, Martín. "The Perils of Taylor Rules.” Journal of Economic Theory, January 2001, 96(1-2), pp. 40-69. 